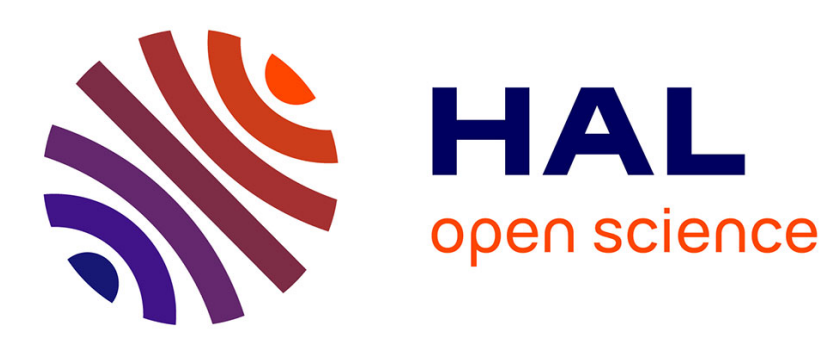

\title{
High-throughput experiment for the rapid screening of organic phase change materials
}

\author{
Clément Mailhé, Stéphane Gorsse, Boèce Thirion, Elena Palomo, Marie
}

Duquesne

\section{- To cite this version:}

Clément Mailhé, Stéphane Gorsse, Boèce Thirion, Elena Palomo, Marie Duquesne. High-throughput experiment for the rapid screening of organic phase change materials. Journal of Thermal Analysis and Calorimetry, 2022, 147 (15), pp.8137-8143. 10.1007/s10973-021-11091-9 . hal-03498842

\section{HAL Id: hal-03498842 \\ https://hal.science/hal-03498842}

Submitted on 21 Dec 2021

HAL is a multi-disciplinary open access archive for the deposit and dissemination of scientific research documents, whether they are published or not. The documents may come from teaching and research institutions in France or abroad, or from public or private research centers.
L'archive ouverte pluridisciplinaire HAL, est destinée au dépôt et à la diffusion de documents scientifiques de niveau recherche, publiés ou non, émanant des établissements d'enseignement et de recherche français ou étrangers, des laboratoires publics ou privés. 


\title{
High-throughput experiment for the rapid screening of organic phase change materials
}

\author{
Clément Mailhé $^{1} \cdot$ Stéphane Gorsse ${ }^{2} \cdot$ Boèce Thirion $^{3} \cdot$ Elena Palomo $^{4,5} \cdot$ Marie Duquesne $^{3}$ (I)
}

Received: 9 March 2021 / Accepted: 24 September 2021

(c) Akadémiai Kiadó, Budapest, Hungary 2021

\begin{abstract}
An emerging dynamic calorimetry method based on infrared thermography (IRT method) has recently proven to be of great interest for the fast establishment of the phase diagrams of binary systems of organic materials (sugar alcohols, fatty acids, fatty alcohols). The methods allowed for their determination in a single 2-h experiment when standard techniques require weeks of measurements hence enabling a significant improvement of the efficiency of material screening processes. As adding a component to the system greatly increases the number of compositions to be studied ( 21 for binary, 231 for ternary assuming a $5 \mathrm{~mol} \%$ increment between compositions), the IRT method may be of even greater use with increasing system complexity. This work then aims at studying the applicability of IRT for the fast establishment of phase diagrams of ternary systems with the lauric (LA), myristic (MA), and palmitic (PA) fatty acids ternary system as an illustrative case. A phase diagram in agreement with the results of the literature and with DSC measurements is established using IRT in a few hoursexperiments instead of weeks to months with standard methods. The obtained results (e.g. $67 \mathrm{~mol} \% \mathrm{LA}+23 \mathrm{~mol} \% \mathrm{MA}+10$ mol\%PA for the eutectic composition, occurrence of a ternary eutectic reaction at $32{ }^{\circ} \mathrm{C}$ ) are promising. This technique also successfully allows for rapid exploration of the phase diagram: reconstruction of the liquidus surface, identification of the eutectic transition, 4-phase equilibrium. IRT is a particularly interesting high-throughput characterization method for the establishment of the phase diagrams of ternary (or higher-order) systems.
\end{abstract}

Keywords Infrared thermography $\cdot$ Phase diagram $\cdot$ DSC $\cdot$ Ternary systems $\cdot$ Eutectic transition

\section{Introduction}

Phase diagrams are essential tools in materials science. They define areas of existence of phases according to pressure, temperature, and chemical composition for pure and

Marie Duquesne

marie.duquesne@enscbp.fr

1 Université de Bordeaux, I2M Bordeaux, Bâtiment A11, 351 cours de la Libération, 33405 Talence, France

2 CNRS, Univ. Bordeaux, Bordeaux INP, ICMCB, 33600 Pessac, France

3 Bordeaux INP, CNRS, Université de Bordeaux, I2M, Bât A11, 351 cours de la Libération, 33400 Talence, France

4 Centre for Cooperative Research on Alternative Energies (CIC energiGUNE), Basque Research and Technology Alliance (BRTA), Alava Technology Park, 01510 Vitoria-Gasteiz, Spain

5 Ikerbasque, Basque Foundation for Science, 48013 Bilbao, Spain multi-component systems of materials [1]. Their establishment hence provides valuable information to the scientist, often decisive depending on the field of application [2-4]. Standard experimental methods are categorized as either static or dynamic and rely on the observation of a material property (structural, physical, thermal, chemical ...) at different temperature levels (static) or during a temperature profile (dynamic) [5]. For multi-component systems of materials, the determination of an accurate phase diagram requires a large number of experiments making the phase diagram establishment process a rather time-consuming task. Indeed, traditional methods are only able to perform single sample characterization which is not competitive in an industrial development context. The use of phase change materials (PCM) in thermal energy storage (TES) is a good example to illustrate the benefits of phase diagrams. Indeed, the thermal behavior and melting temperature of PCMs are critical properties that can be tailored using blends instead of single component PCMs. It is then of great importance with respect to the performance of finding blends without solidification 
interval, i.e. with congruent melting or eutectic. Therefore, phase diagrams are the road map to select blends with the desired melting temperature and solidification behavior. However, the exploration of the vast compositional space of multicomponent systems requires a large number of samples (e.g. 231 for a ternary system and 1771 for quaternary system with a $5 \mathrm{~mol} \%$ step increment) [6]. To speed up the exploration, we need high throughput techniques that can be automated, parallelized, and miniaturized [7], which is not the case for the most common techniques being used such as differential scanning calorimetry (DSC), differential thermal analysis (DTA), or X-ray powder diffraction (XRD) [1, 2, $5,8-12]$. To address this issue, modeling tools are commonly employed to predict multi-component phase diagrams from known lower-order subcomponent systems [13, 14]. While this approach is well developed for metals and alloys, organic materials are still poorly described in the literature and thermodynamic databases are not currently available for these systems. In order to overcome the limits of traditional methods, a high throughput technique based on infrared thermography (IRT method) was developed. Its application for the assessment of binary phase diagrams has shown interesting results for mixtures of sugar alcohols [15] and of fatty acids and fatty alcohols [16], respectively $[15,16]$. It allowed for the rapid screening of the liquidus temperature in a single 2-h experiment while traditional methods would require weeks of measurements. Due to its promising aspect, the method is currently undergoing a campaign of parametric studies [17-19] to enhance and optimize its performance. As the more components, a system includes the more timeconsuming the phase diagram establishment process is, the IRT method might be of increasing interest with the growing complexity of the system.

In this paper, we present high-throughput experiments that allow simultaneous measurement of the liquid-solid transition temperatures of several blends, and to quickly establish the liquidus surface of multi-component systems. Our method combines materials libraries with discrete compositions and rapid tests enabling to accelerate the screening tests. This approach is applied to the fatty acids (FA) ternary system with Lauric acid, Myristic acid, and Palmitic acid. The validity of the results is discussed by comparison with DSC measurements and with data from the literature.

\section{Materials and methods}

\section{Materials}

The ternary system studied in this work is the Lauric acid + Myristic acid + Palmitic acid system. Information regarding the properties of the pure compounds is given in Table 1. Indicated melting temperatures and their corresponding standard deviation are obtained by DSC following the protocol described hereafter. Temperature ranges found in the literature [20-29] are also stated for comparison.

Each binary system obtainable from the 3 materials considered has already been studied with the IRT method [ 30 , 31 and the results obtained have been validated by comparison with DSC measurements and literature data. With a $5 \mathrm{~mol} \%$ increment, the number of samples to be studied is 231 ( 171 to be studied in this work and the 60 other samples being studied for the establishment of the binary systems phase diagrams in previous work [30,31]). Although this number may still appear high for standard methods such as DSC, analyzing all the samples can be managed in a matter of hours with the IRT method.

The preparation of each sample is made using a METTLER TOLEDO weighing scale with a $0.03 \mathrm{mg}$ uncertainty. Batches of $200 \mathrm{mg}$ are prepared by first weighing the first compound in its solidified form after being melted in an aluminum weighing pan and then weighing the second compound following the same process.

\section{IRT method}

A recent innovative high-throughput technique based on infrared thermography has recently proven to be particularly adapted for the fast establishment of phase diagrams of binary systems of organic materials [15-19, 31]. The infrared thermography (IRT) method has successfully provided the phase diagrams of sugar alcohols, fatty acids, and fatty alcohols binary systems in a single experiment of less than two hours. Its advantage resides in its ability to study multiple samples at a time, hence greatly accelerating the step of phase change characterization. The process of phase diagram establishment requires the study of an extensive amount of compositions. If for binary systems a reliable determination can be made based on a manageable number
Table 1 Properties of the pure compounds studied

\begin{tabular}{llllll}
\hline Material & Acronym & Supplier & Purity $/ \%$ & \multicolumn{2}{l}{ Melting temperature $/{ }^{\circ} \mathrm{C}$} \\
\cline { 5 - 6 } & & & This work & {$[20-29]$} \\
\hline Lauric acid & LA & Acros Organics & 99 & $43.40 \pm 0.11$ & $42.44-45.29$ \\
Myristic acid & MA & Acros Organics & 99 & $53.48 \pm 0.04$ & $55.23-55.58$ \\
Palmitic acid & PA & Sigma-Aldrich & 99 & $62.14 \pm 0.02$ & $61.45-64.35$ \\
\hline
\end{tabular}


of samples, the requirements become increasingly demanding as new compounds are added to the system. In that frame, the IRT method, whose efficiency has already been demonstrated for binary systems [15-19, 31], could prove to be of great interest for the phase diagram establishment of systems including more than two compounds. It could also effectively participate in the large gathering of experimental data, supplying modeling databases with useful information regarding organic materials. The principle of the method has been thoroughly described in [15] resulting from various studies [32] dedicated to the study of phase transition processes for the study and development of phase change materials. The presented experimental parameters have been chosen according to the results obtained in these previous studies. The readers are encouraged to consult these studies for an in-depth understanding of the choices made regarding the operating conditions.

Multiple samples of the system of materials are deposited in the form of droplets onto a thermally conductive plate. This plate is then submitted to a slow heating ramp monitored with a thermocouple placed on the support plate. In this study, the heating rate is set at $1{ }^{\circ} \mathrm{C} \mathrm{min}^{-1}$ from 20 to $75^{\circ} \mathrm{C}$ in order to encompass the majority of occurring transitions. An infrared camera placed above the plate simultaneously records the thermal scene as the samples are submitted to the ramp. The camera used in this work is the FLIR $\mathrm{X} 6580 \mathrm{SC}$, and the acquisition rate is set at $7 \mathrm{~Hz}$. An image sequence is then obtained containing the data of 30 to 40 samples at a time in a single experiment lasting less than $2 \mathrm{~h}$. Considering the $5 \mathrm{~mol} \%$ increment chosen for this work, the 171 samples can all be studied within $12 \mathrm{~h}$ of experiments. Figure 1 presents a scheme of the experimental setup.

As only the data of the samples is useful and as each sample is represented by hundreds of pixels, image, and signal processing techniques are applied prior to analyzing the data in order to facilitate the interpretation of the results. As explained in [15], the structure modifications occurring during the phase change process induce a variation of the emissivity of the material. This change in emissivity can then be noticed in the infrared signal recorded by the camera and consequently lead to the identification of phase transitions. The detail of applied processes is available in [15]. Following their implementation, the data interpretation for each sample consists in detecting abrupt trend changes in 2-3 eigenfunctions, attributed to phase transitions. The eigenfunctions are obtained through a singular value decomposition (SVD), which is a common tool in signal processing when dealing with large multi-variable datasets that allow separating variables and highlighting variations in the raw data.

Figure 2a shows the raw infrared signals for a sample of pure Palmitic acid. As is, the signals are not manageable and cannot allow for a reliable interpretation of transition

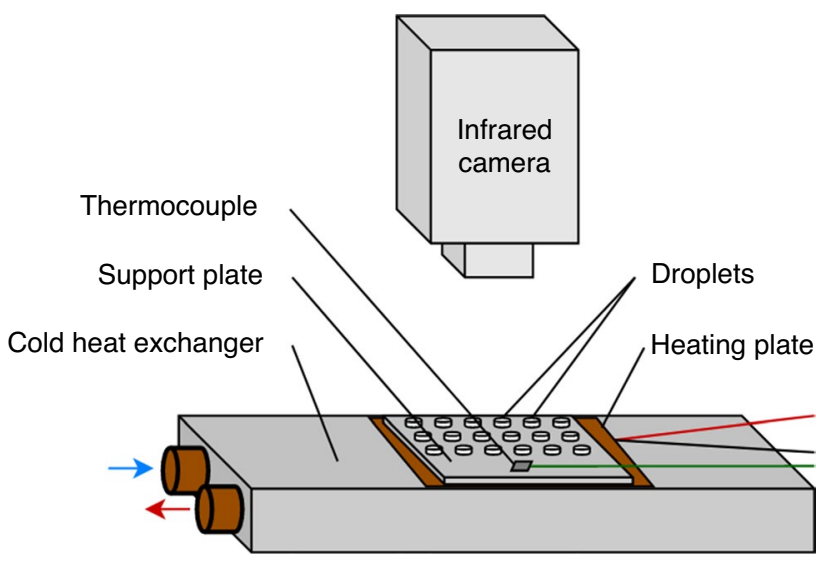

Fig. 1 Scheme of the experimental setup

temperatures. In that case, a transition can either be misplaced or lost in the great amount of data gathered. After SVD, we notice in Fig. $2 b$ that the first three eigenfunctions show easily identifiable variations which greatly facilitates the interpretation. As demonstrated in [15], the first three eigenfunctions are sufficient to detect most occurring transitions, the first eigenfunction generally being a representation of the average signal while the other two express variations from it. This consideration is all the more valid when several transitions occurring successively have to be distinguished in the cluster of data (which is often the case for mixture samples).

\section{Validation}

The IRT method is an emerging technique whose results are to be validated by measurements obtained by established standard methods. The most commonly used for phase diagram establishment is DSC. It is consequently the technique used in this work to validate the results obtained with the IRT method as well as the results extracted from literature.

The device used is a DSC 131 model provided by SETARAM, calibrated for reliable measurements in the 20-330 ${ }^{\circ} \mathrm{C}$ range using Gallium (Purity: $99.9999 \%$ ), Indium (Purity: 99.995\%), Tin (Purity: 99.999\%), and Lead (Purity: 99.999\%). The samples passing through the DSC come from the same batches used for the samples of the IRT experiment. A total of 22 compositions are chosen in order to provide an adequate depiction of the ternary phase diagram as analyzing all the samples studied in the IRT experiment would not be possible due to the time-consuming aspect of the DSC. For each sample, a mass between 10 and $15 \mathrm{mg}$ is weighed and placed in $30 \mu \mathrm{L}$ aluminum crucibles and 3 heating-cooling cycles are performed at $1{ }^{\circ} \mathrm{C} \mathrm{min}-1$ in order to match the operating conditions of the IRT method. Each cycle begins at $20{ }^{\circ} \mathrm{C}$ and ends at $75{ }^{\circ} \mathrm{C}$ to be sure encompass most occurring transitions. The first cycle is used 
(a)

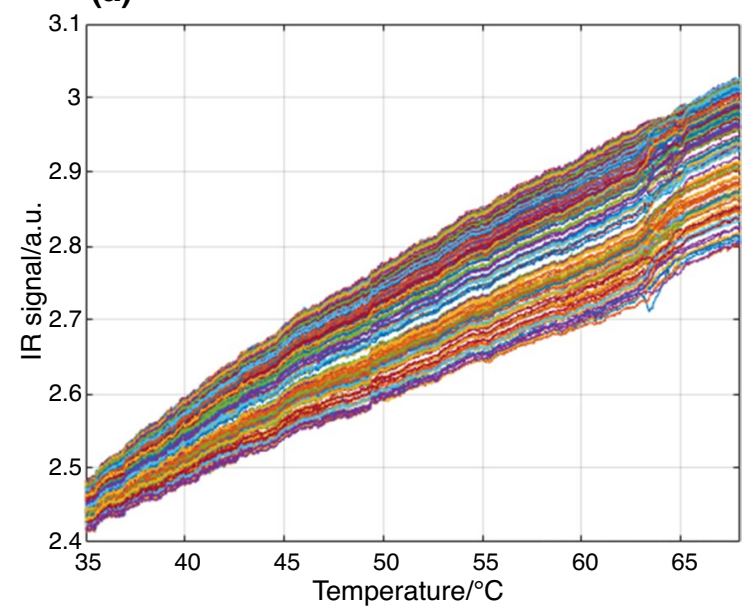

(b)

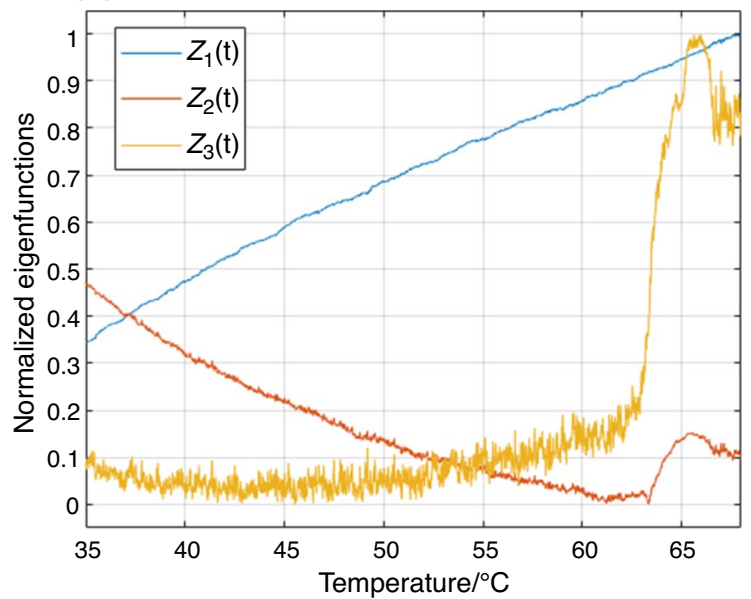

Fig. 2 a Raw infrared signals for a sample of Palmitic acid; $\mathbf{b}$ First three time-eigenfunctions for the same sample.

to ensure the sample adheres to crucible and to delete any thermal history.

The interpretation of the DSC curves is made based on the guidelines in [33] stating that for transitions temperatures, the onset temperature is considered if a clear baseline can be identified and the peak temperature is chosen otherwise.

The liquidus temperatures for 22 blends extracted from IRT and DSC, respectively, are compared in Fig. 3. This graphical representation highlights the good agreement that has been found so far between both techniques.

\section{Results and discussion}

Figure $4 \mathrm{a}$ shows the complex surface connecting the 231 liquidus temperatures obtained by IRT for the LA + MA + PA ternary system. In ternary systems, the liquidus surface bounds two-phase Liquid + Solid $(\mathrm{L}+\mathrm{S})$ fields. Considering that the binary sub-systems involved in this ternary include eutectic and peritectic reactions [30, 34-36], there are numerous twophase regions $(\mathrm{L}+\mathrm{S})$ whose edges meet to form a common line bounding three-phase regions. The most obvious that can be identified in Fig. 4a is the eutectic valleys emerging from the neighboring binary eutectic reactions $\mathrm{L}=\mathrm{LA}+\mathrm{PA}$, $\mathrm{L}=\mathrm{LA}+\mathrm{MA}$, and $\mathrm{L}=\mathrm{MA}+\mathrm{PA}$. Another interesting feature in Fig. 4a is the presence of a minimum at around $32{ }^{\circ} \mathrm{C}$ corresponding to the lowest melting point of the ternary system at $70 \mathrm{~mol} \% \mathrm{LA}+20 \mathrm{~mol} \% \mathrm{MA}+10 \mathrm{~mol} \% \mathrm{PA}$. This reveals the occurrence of either an isomorphous congruent minimum melting or a ternary eutectic reaction $\mathrm{L}=\mathrm{LA}+\mathrm{MA}+\mathrm{PA}$.

In addition to the liquidus surface, the IRT method evidenced isothermal transitions spanning over large composition ranges at around 32,37 , and $51^{\circ} \mathrm{C}$ (Fig. 4b). In ternary

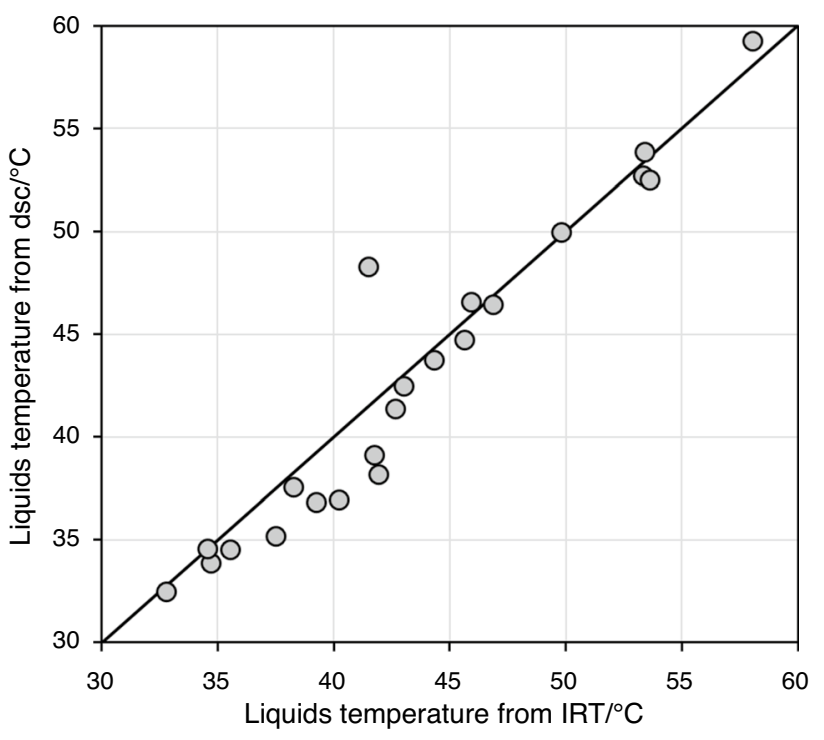

Fig. 3 Graphical representation of the agreement between the IRT method and a standard method (DSC)

systems, 2-dimensional isothermal regions connect the compositions of phases participating in four-phase equilibriums. Even though it is not possible to extract the compositions of the phases from Fig. $4 \mathrm{~b}$, the isotherm detected at around $32{ }^{\circ} \mathrm{C}$ in the LA-rich compositional space allows discriminating the type of phase transition that occurs at this minimum melting temperature as a ternary eutectic transformation. The nature of the other ternary four-phase equilibrium at 37 and $51{ }^{\circ} \mathrm{C}$ cannot be determined with the current data, however, the peritectic reactions extending from the binary sub-systems suggest that ternary four-phase equilibrium are class II, i.e. intermediate between eutectic and peritectic equilibriums, and/or class III, i.e. ternary equivalent of peritectic equilibrium. 


\section{(a)}

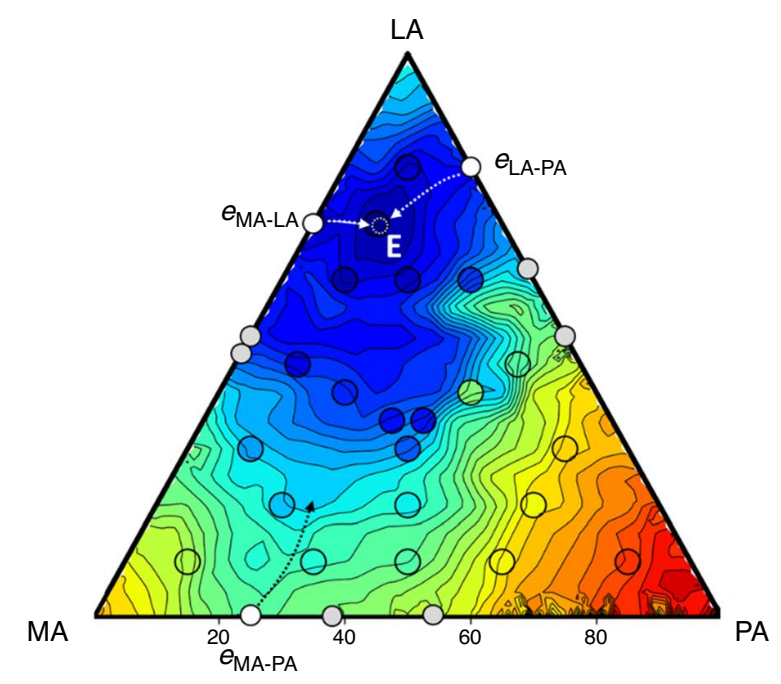

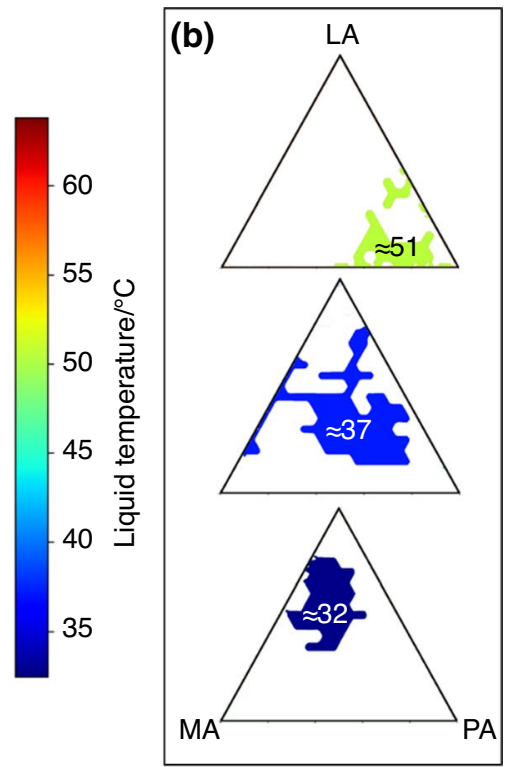

Fig. 4 Phase diagram reconstruction from IRT. a Liquidus surface temperature map of the ternary system LA+MA+PA obtained 231 samples simultaneously analyzed by the IRT method. The DSC results, represented by large circles, are superimposed on the liquidus surface. The same colormap is used for both methods to show the coincidence. The smaller white and gray circles represent invariant

The work presented in [37] shows a DSC-determined ternary eutectic composition of $67.13 \mathrm{~mol} \% \mathrm{LA}+22.83 \mathrm{mo}$ $1 \% \mathrm{MA}+10.05 \mathrm{~mol} \% \mathrm{PA}$ with a melting point around $31^{\circ} \mathrm{C}$. Further DSC analyses aiming at corroborating the observations made with the IRT method, confirm the existence of a eutectic reaction at this composition $(67 \mathrm{~mol} \% \mathrm{LA}+23 \mathrm{~mol}$ $\% \mathrm{MA}+10 \mathrm{~mol} \% \mathrm{PA}$ ) and with a melting point matching the one obtained with IRT (Table 2). In addition, the previously mentioned $37{ }^{\circ} \mathrm{C}$ isothermal region has successfully been retrieved with DSC measurements, at a temperature level consistent with IRT observations. On the other hand, the thermal event at $51{ }^{\circ} \mathrm{C}$ is only detected with the IRT method. The detection appears to be rather reliable considering the small standard deviation but its presence cannot yet be confirmed by DSC. This detection is however, not surprising as similar observations are also made for the binary systems in previous works [30, 31]. reactions in the binary sub-systems (binary eutectics and peritectics). Binary eutectic and ternary eutectics are denoted by e and E, respectively. Dotted arrows are guidelines to visualize the eutectic valleys emerging from the binaries and meeting at the ternary eutectic point. b Ternary four-phase equilibrium at 32,37 and $51^{\circ} \mathrm{C}$

The author in [37] attempts predicting eutectic compositions of multi-compounds systems with thermodynamic modeling. For this system, the predicted eutectic composition for this system was $58.69 \mathrm{~mol} \% \mathrm{LA}+28.68 \mathrm{~mol} \% \mathrm{MA}+$ $12.63 \mathrm{~mol} \% \mathrm{PA}$ which is far off the actual composition determined experimentally. This deviation highlights the limits of modeling techniques and the need for cost-effective and time-efficient experimental methods such as IRT.

With the encouraging results obtained for the establishment of a ternary phase diagram with the IRT method, we can conclude that this method can allow the rapid and efficient screening of complex multi-component systems. The transition detection with the IRT method indeed appears to be quite reliable with a retrieved liquidus showing no discontinuities and isothermal regions detected with acceptable standard deviations, within range of standard DSC measurements and spanning over several distinct

Table 2 Average temperature, standard deviation, and number of samples for the isothermal transitions detected with the IRT method and DSC measurements

\begin{tabular}{lllllllll}
\hline & $\overline{T_{\mathrm{tr} 1}} /{ }^{\circ} \mathrm{C}$ & $\sigma_{\mathrm{tr} 1} /{ }^{\circ} \mathrm{C}$ & $n$ & $\overline{T_{\mathrm{tr} 2}} /{ }^{\circ} \mathrm{C}$ & $\sigma_{\mathrm{tr} 1} /{ }^{\circ} \mathrm{C}$ & $n$ & $\overline{T_{\mathrm{tr} 3} /{ }^{\circ} \mathrm{C}}$ & $\sigma_{\mathrm{trr}} /{ }^{\circ} \mathrm{C}$ \\
\hline IRT & 31.96 & 0.77 & 43 & 37.13 & 0.57 & 49 & 50.77 & 0.62 \\
DSC & 31.93 & 0.58 & 12 & 36.81 & 0.65 & 10 & - & - \\
\hline
\end{tabular}

With $\overline{T_{t r 1}}$ the average transition temperature of transition $\mathrm{n}^{\circ} 1$ in ${ }^{\circ} \mathrm{C}, \sigma_{\mathrm{tr} 1}$ the standard deviation of the transition temperature for the transition $\mathrm{n}^{\circ} 1$ and the $n$ number of samples for which the transition has been detected 
experiments. Now that the proof of concept is done, we can proceed to the screening of other ternary / quaternary systems in order to explore their employability in various applications

\section{Conclusions}

In this work, we have shown that the IRT method is an effective high-throughput technique allowing the automatic, rapid, and low-cost characterization of a broad spectrum of discrete compositions of a blend. It has been successfully implemented for the rapid screening of an $\mathrm{LA}+\mathrm{MA}+\mathrm{PA}$ ternary blend. Its phase diagram obtained in this work consisted of 171 data sets obtained in less than $12 \mathrm{~h}$ of experiments which is considerably less than the time that would have been required with the use of standard methods (weeks/ months). An isotherm detected around $32{ }^{\circ} \mathrm{C}$ in the LA-rich compositional space suggested the occurrence of a ternary eutectic reaction whose location, both in terms of temperature and composition, was confirmed and found to match literature data and DSC measurements. At this eutectic composition, the ternary system behaves like a single phase with a congruent fusion. Being able to rapidly obtain both the eutectic composition and its melting temperature is a tremendous asset of the IRT method. Indeed, it enables the easy identification of material properties in temperature-based applications such as thermal energy storage and motivates the choice to either further study the composition or continue the screening of other systems. This technique also allows for rapid exploration of the phase diagram: reconstruction of the liquidus surface, identification of the eutectic, 4-phase equilibrium. Both pave the way for the modeling and prediction of phase diagrams in these systems and for the rapid screening of the composition space in the search of suitable blends in a wide range of applications.

Acknowledgements This work is carried out in the frame of SUDOKET project and is co-funded by the Interreg Sudoe Programme through the European Regional Development Fund (ERDF). The authors acknowledge them as well as the financial support of Region Nouvelle Aquitaine for subsidizing BioMCP project (Project-2017-1R10209-13023). We also would like to thank CNRS for promoting the I2M Bordeaux-CICe exchanges in the framework of the PICS PHASE-IR project. The authors would also like to thank Valérie Thouard for the administrative and financial management over SUDOKET Project.

\section{References}

1. Campbell FC. Phase Diagrams: Understanding the Basics. ASM International; 2012.
2. Dubost B. Industrial applications and determination of equilibrium phase diagrams for light alloys. Progress Prospects Rev Métallurgie. 1993;90:195-210.

3. Research (U.S.) I for M, Data NML (U S) O of SR, Foundation (U.S.) NS. Applications of Phase Diagrams in Metallurgy and Ceramics: Proceedings of a Workshop Held at the National Bureau of Standards, Gaithersburg, Maryland, January 10-12, 1977. U.S. Department of Commerce, National Bureau of Standards; 1978.

4. Pelton AD. Thermodynamics and phase diagrams of materials Phase transform mater [Internet]. New York: Wiley; 2005. https:// doi.org/10.1002/352760264X.ch1.

5. Inden G. Experimental determination of phase diagrams. In: Turchi PEA, Gonis A, editors. Statics dyn alloy phase transform [Internet]. Boston: Springer; 1994. p. 17-43. https://doi.org/10. 1007/978-1-4615-2476-2_2.

6. Gorsse S, Couzinié J-P, Miracle DB. From high-entropy alloys to complex concentrated alloys. Comptes Rendus Phys. 2018;19:721-36.

7. Miracle D, Majumdar B, Wertz K, Gorsse S. New strategies and tests to accelerate discovery and development of multi-principal element structural alloys. Scr Mater. 2017;127:195-200.

8. Höhne GWH, Hemminger W, Flammersheim H-J. Differential Scanning Calorimetry: An Introduction for Practitioners [Internet]. Berlin: Springer; 1996.

9. Sarge SM, Höhne G, Hemminger W. Calorimetry: fundamentals, instrumentation and applications [Internet]. Hoboken: Wiley$\mathrm{VCH} ; 2014$.

10. Methods of Calorimetry. Calorimetry [Internet]. Wiley; 2014, pp. 9-18. https://doi.org/10.1002/9783527649365.ch01

11. Lewis RNAH, McElhaney RN. Fourier transform infrared spectroscopy in the study of lipid phase transitions in model and biological membranes: practical considerations. Methods Mol Biol Clifton NJ. 2007;400:207-26.

12. Zheng W, Kaiser RI. An infrared spectroscopy study of the phase transition in solid ammonia. Chem Phys Lett. 2007;440:229-34.

13. Kroupa A. Modelling of phase diagrams and thermodynamic properties using Calphad method-development of thermodynamic databases. Comput Mater Sci. 2013;66:3-13.

14. Kattner UR. The Calphad method and its role in material and process development. Tecnol Em Metal Mater E Mineracao. 2016;13:3-15.

15. Palomo del Barrio E, Cadoret R, Daranlot J, Achchaq F. Infrared thermography method for fast estimation of phase diagrams. Thermochim Acta. 2016;625:9-19.

16. Mailhé C, Duquesne M, Palomo del Barrio E, Azaiez M, Achchaq F. Phase diagrams of fatty acids as biosourced phase change materials for thermal energy storage. Appl Sci. 2019;9:1067.

17. Mailhé C, Duquesne M, Mahroug I, Palomo del Barrio E. Improved infrared thermography method for fast estimation of complex phase diagrams. Thermochim Acta. 2019;675:84-91.

18. Mailhé C, Duquesne M. Performance analysis of the infrared thermography method for complex phase diagrams estimation. J Therm Anal Calorim. 2020. https://doi.org/10.1007/ s10973-020-09333-3.

19. Mailhé C, Duquesne M. A fast and low-cost dynamic calorimetric method for phase diagram estimation of binary systems. J Therm Anal Calorim. 2020. https://doi.org/10.1007/s10973-020-09287-6.

20. Kenisarin MM. Thermophysical properties of some organic phase change materials for latent heat storage. A review. Sol Energy. 2014;107:553-75.

21. Maximo GJ, Carareto NDD, Costa MC, dos Santos AO, Cardoso LP, Krähenbühl MA, et al. On the solid-liquid equilibrium of binary mixtures of fatty alcohols and fatty acids. Fluid Phase Equilib. 2014;366:88-98. 
22. Costa MC, Rolemberg MP, Boros LAD, Krähenbühl MA, de Oliveira MG, Meirelles AJA. Solid-liquid equilibrium of binary fatty acid mixtures. J Chem Eng Data. 2007;52:30-6.

23. Zhang Z, Yuan Y, Zhang N, Cao X. Thermophysical properties of some fatty acids/surfactants as phase change slurries for thermal energy storage. J Chem Eng Data. 2015;60:2495-501.

24. Kahwaji S, Johnson MB, Kheirabadi AC, Groulx D, White MA. Fatty acids and related phase change materials for reliable thermal energy storage at moderate temperatures. Sol Energy Mater Sol Cells. 2017;167:109-20.

25. Zhang J-J, Zhang J-L, He S-M, Wu K-Z, Liu X-D. Thermal studies on the solid-liquid phase transition in binary systems of fatty acids. Thermochim Acta. 2001;369:157-60.

26. Cedeño FO, Prieto MM, Espina A, García JR. Measurements of temperature and melting heat of some pure fatty acids and their binary and ternary mixtures by differential scanning calorimetry. Thermochim Acta. 2001;369:39-50.

27. Schaake RCF, van Miltenburg JC, de Kruif CG. Thermodynamic properties of the normal alkanoic acids II. Molar heat capacities of seven even-numbered normal alkanoic acids. J Chem Thermodyn. 1982;14:771-8.

28. Hobi Bordón Sosa F, Dorighello Carareto ND, Maximo GJ, de Meirelles AJA, Costa MC. Solid-liquid equilibrium of binary systems containing fatty acids and fatty alcohols using differential scanning calorimetry. J Chem Eng Data. 2019;64:5017-27.

29. Han L, Ma G, Xie S, Sun J, Jia Y, Jing Y. Thermal properties and stabilities of the eutectic mixture: 1,6-hexanediol/lauric acid as a phase change material for thermal energy storage. Appl Therm Eng. 2017;116:153-9.

30. Duquesne M, Mailhé C, Ruiz-Onofre K, Achchaq F. Biosourced organic materials for latent heat storage: An economic and ecofriendly alternative. Energy. 2019;188:116067.
31. Mailhé C, Achchaq F, Duquesne M. Applications of an infrared thermography method for solid-liquid equilibria modeling of organic binary systems. Thermochim Acta. 2020;687:178580.

32. Duquesne M, Godin A, Palomo del Barrio E, Daranlot J. Experimental analysis of heterogeneous nucleation in undercooled melts by infrared thermography. Quant InfraRed Thermogr J. 2015;12:112-26.

33. Boettinger WJ, Kattner UR, Moon K-W, Perepezko J. NIST Recommended practice guide: DTA and heat-flux DSC measurements of alloy melting and freezing I NIST. Methods Phase Diagr Determ [Internet]. 2006 [cited 2019 Jan 31]; https://www.nist.gov/ publications/nist-recommended-practice-guide-dta-and-heat-fluxdsc-measurements-alloy-melting-and

34. Costa MC, Rolemberg MP, Meirelles AJA, Coutinho JAP, Krähenbühl MA. The solid-liquid phase diagrams of binary mixtures of even saturated fatty acids differing by six carbon atoms. Thermochim Acta. 2009;496:30-7.

35. Costa MC, Sardo M, Rolemberg MP, Coutinho JAP, Meirelles AJA, Ribeiro-Claro P, et al. The solid-liquid phase diagrams of binary mixtures of consecutive, even saturated fatty acids. Chem Phys Lipids. 2009;160:85-97.

36. Costa MC, Sardo M, Rolemberg MP, Ribeiro-Claro P, Meirelles AJA, Coutinho JAP, et al. The solid-liquid phase diagrams of binary mixtures of consecutive, even saturated fatty acids: differing by four carbon atoms. Chem Phys Lipids. 2009;157:40-50.

37. Ke H. Phase diagrams, eutectic mass ratios and thermal energy storage properties of multiple fatty acid eutectics as novel solidliquid phase change materials for storage and retrieval of thermal energy. Appl Therm Eng. 2017;113:1319-31.

Publisher's Note Springer Nature remains neutral with regard to jurisdictional claims in published maps and institutional affiliations. 